\title{
Tuberous Sclerosis Complex Associated Lymphangioleiomyomatosis Presenting with Spontaneous Pneumothorax and Renal Angiomyolipomas
}

\author{
Rahman $\mathrm{MM}^{1}$, Sarker $\mathrm{SM}^{2}$, Musa $\mathrm{MI}^{3}$, Habib FB ${ }^{4},{ }^{*}$ Hasan $\mathrm{MN}^{5}$, Mosharraf Hossain $\mathrm{AKM}^{6}$
}

\begin{abstract}
Tuberous sclerosis complex (TSC) is a rare autosomal dominant disorder manifested by involvement of multisystem including skin, central nervous system, heart, kidneys and eyes. Lymphangioleiomyomatosis (LAM) is also a multisystem disorder that primarily affects the lungs. We report a case of tuberous sclerosis complex associated lymphangio-leiomyomatosis (TSC-LAM) in a 26-year-old female patient who was presented with spontaneous pneumothorax and renal angiomyolipomas. In clinical examination; We found multiple angiofibromas over her face, shagreen patches over upper and lower back and ungual fibromas in both fingers and toes. HRCT of chest revealed right sided pneumothorax with multiple thin walled cysts in both lungs. Ultrasonogram (USG) and Computer Tomography (CT) scan of abdomen revealed bilateral angiomyolipomas. We managed her pneumothorax with intercostal chest tube drainage and oxygen inhalation.
\end{abstract}

Keywords: Tuberous sclerosis complex, lymphangioleiomyomatosis, angiomyolipoma, angiofibroma, shagreen patch, ungual fibroma, pneumothorax.

\section{INTRODUCTION}

Tuberous sclerosis complex (TSC) is a autosomal dominant disorder characterized by multiple benign

1. Mohammed Mirazur Rahman, Phase-B resident (Pulmonology), BSMMU,Dhaka.

2. Shish Mohammad Sarkar, Phase-B resident (Pulmonology), BSMMU,Dhaka.

3. Manzurul Ibrahim Musa, Phase-B resident (Pulmonology), BSMMU,Shahbag,Dhaka.

4. Farjana-Binte-Habib, Lecturer (Microbiology), Department of Microbiology, Shaheed Tajuddin Ahmad Medical College, Gazipur,Dhaka

5. ${ }^{*} \mathrm{Md}$. Nazmul Hasan, Assistant Professor, Department of Internal Medicine, BSMMU, Shahbag, Dhaka, nazmul_31st@yahoo.com

6. Professor (Dr) AKM Mosharraf Hossain, Professor and Chairman, Department of Respiratory Medicine, BSMMU

*For correspondence hamartomas of the skin, brain, eyes, heart, lungs, liver and kidneys. ${ }^{1,2}$ Incidence of TSC is approximately 1 in 5000 to 10,000 live births. ${ }^{3}$ It is caused by a mutation in either the TSC1 gene or the TSC2 gene. De novo mutations account for approximately 80 percent of TSC cases. ${ }^{4}$ Lymphangioleiomyomatosis (LAM) is a multisystem disorder that primarily affects the lung. LAM can occur sporadically (sporadic-LAM) or in association with TSC (TSC-LAM). LAM commonly affects women and is characterized by widespreadpulmonary proliferation of abnormal smooth-muscle cells and cystic changes within the lung parenchyma. ${ }^{5}$ LAM is usually diagnosed during early adulthood and is initially manifested by dyspnea or pneumothorax.Angiomyolipoma (AML) is a benign renal neoplasm composed of fat, vascular and smooth muscle elements. Angiomyolipomas occur in $80 \%$ patients with TSC. 6,7 USG, computed tomography (CT) or magnetic resonance imaging (MRI) can detect AMLs easily. About $40 \%$ of AMLs are symptomatic ${ }^{8}$ and they can present as flank pain, palpable abdominal mass or with hematuria. Most of the AMLs have a benign course and patients can be treated conservatively.

\section{CASE REPORT}

A 26-year-old female was admitted at Department of Respiratory Medicine of Bangabandhu Sheikh Mujib Medical University with the complaints of shortness of breath, cough and right sided chest pain for 3 weeks. She had history of recurrent abdominal pain for last 2 years and patiend had multiple brown lesions over her face and all of family members were well.

On examination multiple small brown papules were noted over the face consistent with angiofibromas (Figure 1), multiple shagreen patches (hyperpigmented plaque)were present over the upper and lower back (Figure 2) and ungualfibromas were present in both fingers and toes (Figure 3). Examination of chest revealed features of right sided pneumothorax and abdomen revealed ill defined mass in left hypochondriac region. High resolution CT scan of chest (HRCT) revealed right sided pneumothorax with multiple thin walled cystic lesions with variable sizes in both lung fields (Figure 4). Ultrasound abdomen 


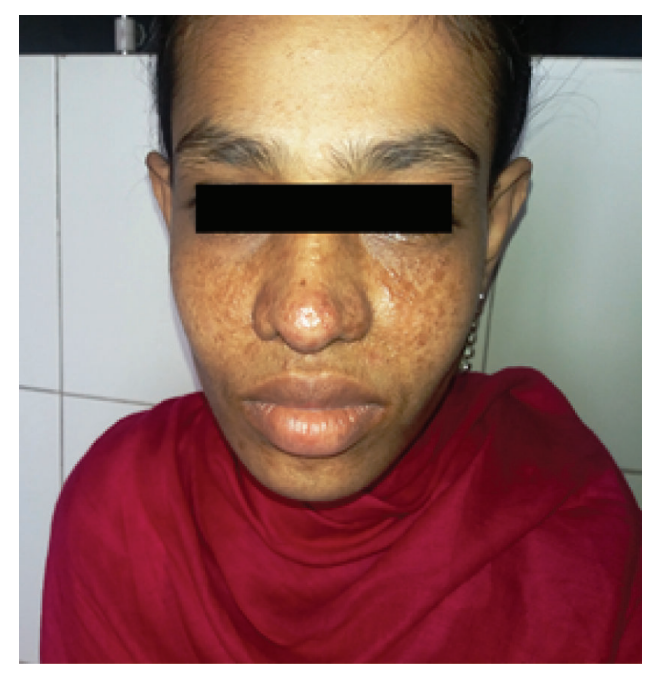

Figure 1: Angiofibromas

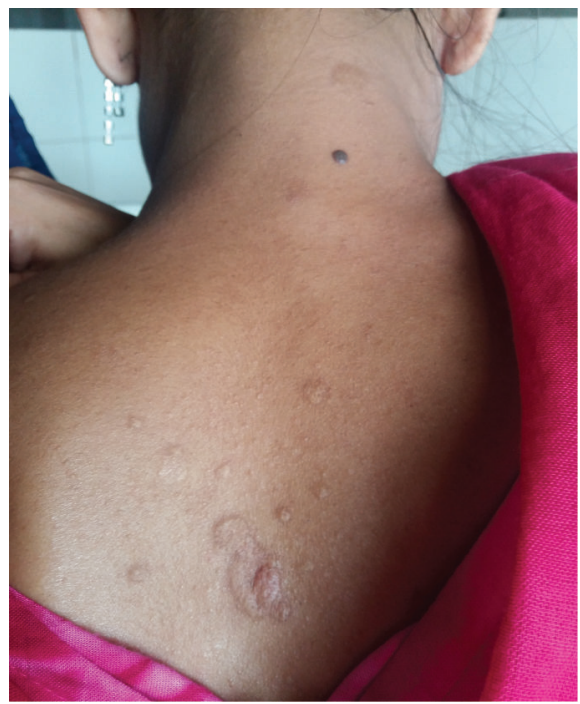

Figure 2: Shagreenpatches (Hyperpigmented plaque)

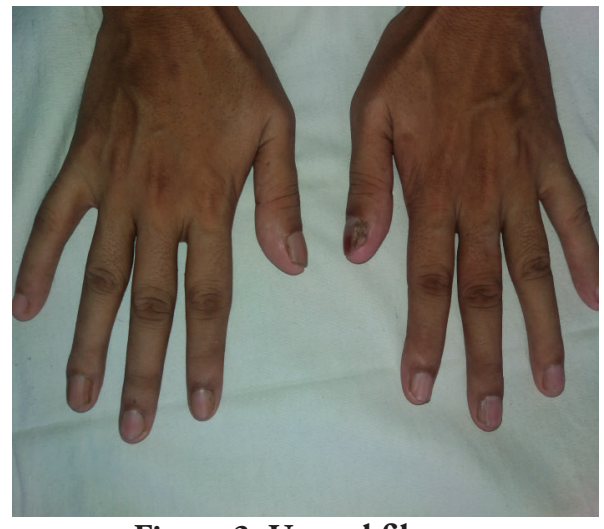

Figure 3: Ungual fibromas

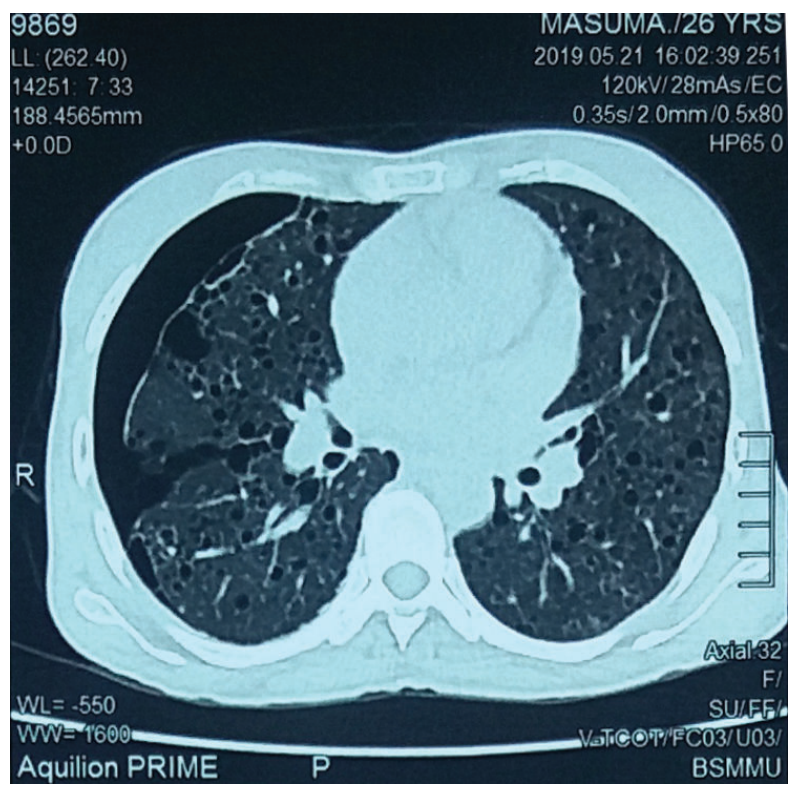

Figure 4: HRCT scan of chest revealed right sided pneumothorax with multiple thin walled cystic lesions with variable sizes in both lung fields

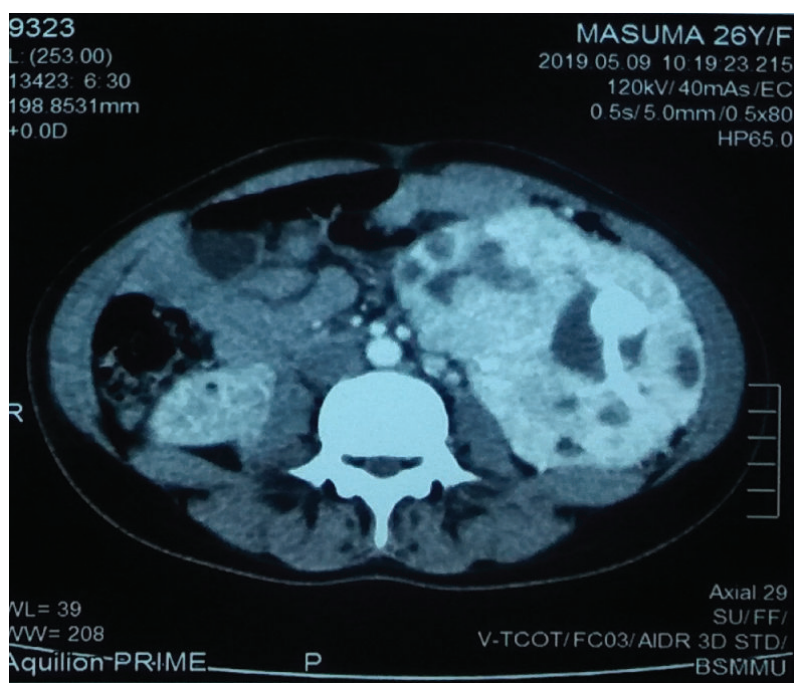

Figure 5: CT scan of abdomen revealed bilateral angiomyolipomas, right measured $4.2 \times 3.9 \times 3.1 \mathrm{~cm}$ while left measured $16.4 \times 11.3 \times 6.8 \mathrm{~cm}$

showed left kidney is enlarged in size and distorted in shape and there are diffuse hyperechoic soft tissue lesions are occupying almost whole of the both renal paranchyma. CT abdomen revealed bilateral angiomyolipomas, right measured $4.2 \times 3.9 \times 3.1 \mathrm{~cm}$ while left measured $16.4 \times 11.3 \times 6.8 \mathrm{~cm}$ and right adnexal cyst (Figure 5). Other biochemical, haematological and echocardiogram as well as MRI of brain were normal. A diagnosis of tuberous 
sclerosis complex associated lymphangioleiomyomatosis was made. She was managed initially with intercostal chest tube drainage for right sided pneumothoraxand consulted urologist and nephrologist for further management of angiomyolipomas. Her IQ assessment was done by applying "Wechsler Abbreviated Scale for Intelligence ${ }^{\mathrm{TM}}$ " (WASI ${ }^{\mathrm{TM}}$ ) and she had mild mental retardation (score-53).

\section{DISCUSSION}

Tuberous sclerosis complex (TSC) is an autosomal dominant disorder that is characterized by pleomorphic features involving many organ systems, including multiple benign hamartomas of the brain, eyes, heart, lungs, liver, kidneys and skin. ${ }^{9}{ }^{9} 10,11$ It is caused by a mutation in either the TSC1 gene or the TSC2 gene. De novo mutations occurs approximately 80 percent of TSC cases.TSC is diagnosed on the basis of genetic or clinical diagnostic criteria (major and minor). ${ }^{12}$ Our patient has five clinical features of major diagnostic criteria and these are multiple angiofibromas, shagreen patches, multiple ungula fibromas, angiomyolipas and lymphangioleiomyomatosis. In most cases diagnosis should be possible using established clinical criteria. About 10 to $25 \%$ of patients with TSC have no mutation identified by conventional genetic testing and a normal result does not exclude TSC or have any effect on the use of clinical diagnostic criteria to diagnose TSC ${ }^{12}$. The utility of molecular testing is limited by the cost.Our patient has been suffering from recurrent lower abdominal pain for last two years and with these complaints she was consulted with several physicians. After doing USG and contrast enhanced CT scan of abdomen, bilateral renal angiomyolipomas were found.LAM is a later manifestation during the course of TSC and symptoms generally develop in the third decade of life. Renal AMLs are visualized on abdominal CT scan, are more frequent in patients with TSC-LAM (often $>80$ percent) compared with sporadic-LAM (30 percent). ${ }^{13,14,15}$ She has recent history of shortness of breath and for evaluation of her shortness of breath we have done chest X-ray posterior anterior view and HRCT of chest. There we found right sided pneumothorax with multiple thin walled cystic lesions in both lungs. These radiological features are very much consistent with pulmonary manifestation of LAM.Several studies have reported pulmonary cysts in TSC-LAM identical to those seen in sporadic-LAM. ${ }^{16,17,18}$ Cysts are thin-walled, multiple ( $\geq$ 10), diffuse, round, well-defined and bilateral. A clinical diagnosis of TSC-LAM is typically made by identifying characteristic HRCT findings in patients with an established diagnosis of TSC. ${ }^{12,19,20}$ The presence of an AML and/or elevated vascular endothelial growth factor-D (VEGF-D; $\geq 800 \mathrm{pg} / \mathrm{mL}$ ) confirm the diagnosis of LAM. ${ }^{19,20}$

General measures used to treat TSC-LAM include avoidance of cigarette smoking, supplemental oxygen for hypoxemia, pulmonary rehabilitation and bronchodilators when indicated. ${ }^{21,22}$ Oestrogen containing medications should be avoided and patients should be informed about the increased risks associated with pregnancy including pneumothorax, lung disease progression and hemorrhage into angiomyolipomas. Hormonal therapy has been used in its treatment including oophorectomy, tamoxifen, $\mathrm{GnRH}$ agonists and progesterone therapy. ${ }^{20} \mathrm{~A}$ recent and promising systemic therapy is a mTOR (mammalian target of rapamycin) inhibitor called sirolimus. ${ }^{23}$ Inhibition of the mTOR protein prevents proliferation of LAM cells. ${ }^{23}$ Clinical trials have shown reduction in AML size and slowing of lung function decline in patients with TSC and LAM. $^{23}$ An enlarging AML can distort the renal architecture and may cause renal failure. ${ }^{24}$ AML larger than $4 \mathrm{~cm}$ is at risk for a potentially catastrophic hemorrhage. Dysmorphic blood vessels in the AML often form microaneurysms, which may rupture and result in renal hemorrhage. ${ }^{25}$ Surgical resection is avoided whenever possible in order to preserve renal function. AMLs that are more than 3 to $4 \mathrm{~cm}$ in diameter can be treated successfully by embolization. ${ }^{25}$

\section{CONCLUSIONS}

The prognosis for individuals with TSC is variable and depends on the severity of symptoms. TSC-LAM is a progressive disorder. The reported case had five clinical features of major diagnostic criteria and these are-multiple angiofibromas, shagreen patches, multiple ungula fibromas, angiomyolip as and lymphangioleiomyomatos is. We also found right sided pneumPothorax with multiple thin walled cyst in both lungs. Bilateral angiomyolipomas were also detected by USG and CT scan of abdomen. Pneumothorax of patients was managed by intercostal chest tube drainage and oxygen inhalation. Patients with TSC-LAM were monitored for progressive lung function decline with pulmonary function testing and for the development of complications.

\section{Conflicts of interest:}

There are no conflicts of interest. 


\section{REFERENCES}

1. Von Ranke FM, Zanetti G, e Silva JL, et al. Tuberous Sclerosis Complex: State-of-the-Art Review with a Focus on Pulmonary Involvement. Lung 2015; 193:619.

2. Henske EP, Jóźwiak S, Kingswood JC, et al. Tuberous sclerosis complex. Nat Rev Dis Primers 2016; 2:16035.

3. Osborne JP, Fryer A, Webb D. Epidemiology of tuberous sclerosis. Ann N Y AcadSci 1991; 615:125.

4. Au KS, Williams AT, Roach ES, et al. Genotype/ phenotype correlation in 325 individuals referred for a diagnosis of tuberous sclerosis complex in the United States. Genet Med 2007; 9:88.

5. Ryu JH, Moss J, Beck GJ, et al. The NHLBI lymphangioleiomyomatosis registry: Characteristics of 230 patients at enrolment. Am J RespirCrit Care Med 2006;173:105-11.

6. Debora SL, Jozwiak S, Franz DN, et al. Mutational analysis in a cohort of 224 tuberous sclerosis patients indicates increased severity of TSC2, compared with TSC1, disease in multiple organs. Am J Hum Genet 2001;68:64-80.

7. Ewalt DH, Sheffield E, Sparagana SP, Delgado MR, Roach ES. Renal lesion growth in children with tuberous sclerosis complex. J Urol 1998;160:141-5.

8. Cohen MD. Genitourinary tumours. In: Cohen MD, ed. Imaging of Children With Cancer. St Louis, Mo: Mosby Year Book; 1992:552-88.

9. Crino PB, Nathanson KL, Henske EP. The tuberous sclerosis complex. N Engl J Med 2006; 355:1345.

10. Schwartz RA, Fernández G, Kotulska K, Jóźwiak S. Tuberous sclerosis complex: advances in diagnosis, genetics, and management. J Am AcadDermatol 2007; 57:189.

11. Curatolo P, Bombardieri R, Jozwiak S. Tuberous sclerosis. Lancet 2008; 372:657.

12. Northrup H, Krueger DA, International Tuberous Sclerosis Complex Consensus Group. Tuberous sclerosis complex diagnostic criteria update: recommendations of the 2012 international tuberous sclerosis complex consensus conference. Pediatr Neurol 2013; 49:243.

13. Ryu JH, Moss J, Beck GJ, et al. The NHLBI lymphangioleiomyomatosis registry: characteristics of 230 patients at enrollment. Am J RespirCrit Care Med 2006; 173:105.

14. Chu SC, Horiba K, Usuki J, et al. Comprehensive evaluation of 35 patients with lymphangioleiomyomatosis. Chest 1999; 115:1041.
15. Bosniak MA, Megibow AJ, Hulnick DH, et al. CT diagnosis of renal angiomyolipoma: the importance of detecting small amounts of fat. AJR Am J Roentgenol 1988; $151: 497$.

16. Franz DN, Brody A, Meyer C, et al. Mutational and radiographic analysis of pulmonary disease consistent with lymphangioleiomyomatosis and micronodularpneumocyte hyperplasia in women with tuberous sclerosis. Am J RespirCrit Care Med 2001; 164:661.

17. Moss J, Avila NA, Barnes PM, et al. Prevalence and clinical characteristics of lymphangioleiomyomatosis (LAM) in patients with tuberous sclerosis complex. Am J RespirCrit Care Med 2001; 164:669.

18. Adriaensen ME, Schaefer-Prokop CM, Duyndam DA, et al. Radiological evidence of lymphangioleiomyomatosis in female and male patients with tuberous sclerosis complex. ClinRadiol 2011; 66:625.

19. McCormack FX, Gupta N, Finlay GR, et al. Official American Thoracic Society/Japanese Respiratory Society Clinical Practice Guidelines: Lymphangioleiomyomatosis Diagnosis and Management. Am J RespirCrit Care Med 2016; 194:748.

20. Johnson SR, Cordier JF, Lazor R, et al. European Respiratory Society guidelines for the diagnosis and management of lymphangioleiomyomatosis. EurRespir J 2010; 35:14.

21. The LAM foundation. http://www.thelam foundation.org (accessed Apr 2013).

22. Hohman DW, Noghrehkar D, Ratnayake S. Lymphangioleiomyomatosis: a review. Eur J Intern Med 2008;19:319-24.

23. Bissler JJ, McCormack FX, Young LR, et al. Sirolimus for angiomyolipoma intuberous sclerosis complex or lymphangioleiomyomatosis. N Engl J Med2008;358:140-51.

24. Dickinson M, Ruckle H, Beaghler M, Hadley HR. Renal angiomyolipoma: Optimal treatment based on size and symptoms. ClinNephrol 1998;49:281-6.

25. Ewalt DH, Diamond N, Rees C, et al. Longterm outcome of transcatheter embolization of renal angiomyolipomas due to tuberous sclerosis complex. J Urol 2005;174:1764-6.

26. Zak S, Mokhallati N, Su W, et al. Lymphangioleiomyomatosis Mortality in Patients with Tuberous Sclerosis Complex. Ann Am ThoracSoc 2019; 16:509.

27. Amin S, Lux A, Calder N, et al. Causes of mortality in individuals with tuberous sclerosis complex. Dev Med Child Neurol 2017; 59:612. 